\title{
Entre narrativas e narradores: viver no campo em Marechal Cândido Rondon na década de 1980
}

\author{
Paloma Mariana Caetano
}

Resumo: O artigo trata de questões vivenciadas em Marechal Cândido Rondon-PR, entre as décadas de 1970 e 1980, envolvendo pequenos proprietários e o modo como percebiam e tratavam suas condições de vida. Para tal investigação, destaquei as evidências sobre essa problemática, presente nas fontes (correspondências do acervo do deputado Kirinus, arquivadas no CEPEDAL/UNIOESTE). A intenção foi analisar os sentidos expressos nessas narrativas, vendo como esses agricultores sugerem um universo de relações em que se veem inseridos, focalizando, principalmente, necessidades e expectativas em seus limites classistas. O pedido de bolsa de estudo para os filhos chamou a atenção, apontando associações com outros elementos da experiência desses sujeitos. Algo que indicou um processo de mudanças mais amplo, em que se incluem as alterações nas relações de produção no campo e as desiguais possibilidades de capitalização das atividades agropecuárias e de intensificação de expropriações rurais, envolvendo trabalhadores e certos proprietários empobrecidos.

Palavras-chave: pequenos proprietários; narrativas; vida no campo; Marechal Cândido Rondon.

\footnotetext{
Graduanda do Curso de História/UNIOESTE-Campus de Marechal Cândido Rondon-PR. Pesquisadora do Programa de Iniciação Científica Voluntária, com projeto intitulado "Entre narrativas e narradores: trabalhadores e proprietários rurais em Marechal Cândido Rondon na década de 1980", sob orientação da Profa. Dr ${ }^{a}$. Sheille Soares de Freitas. E-mail: palomacaetano07@hotmail.com
} 
Abstract: The article discusses questions experienced in Marechal Cândido Rondon-PR between the 1970s and 1980s, involving small farmers and how they perceived and understood their living conditions. For this research, its evidences were highlighted according to the problematic present sources (letters from the collection of Mr. Kirinus, filed in CEPEDAL/UNIOESTE). The intention was to analyze the meanings expressed in these narratives, seeing how these farmers suggest a universe of relationships in which they are inserted, focusing mainly on their needs and expectations in classist boundaries. Applications for scholarships for the children drew ttention, pointing associations with other elements of the experience of these people. Something that indicated a wider process of changes in which modifications in the relations of production in the country and unequal possibilities capitalization of agricultural activities and intensification of rural expropriations, involving workers and certain impoverished farmers.

Keywords: smallholders; narratives; rural life; Marechal Cândido Rondon. 
"19.10.83,

Vila Margarida, M. C. Rondon

Prezado Amigo e Companheiro Gernote Kirinus, eu venho pedir um favor para ti se for possível"2

O presente trabalho tem como objetivo apresentar as principais propostas e considerações da pesquisa de Iniciação Científica, vinculada ao Grupo de Pesquisa História Social do Trabalho e da Cidade, que possui como finalidade analisar o modo de vida daqueles que residiam em Marechal Cândido Rondon - PR, entre o final da década de 1970 e durante a década de 1980.

Inicialmente, essa questão foi formulada no decorrer da higienização de correspondências (enviadas e recebidas) entre a população da região Oeste do Paraná e o deputado Gernote Kirinus, doadas para a composição do Acervo do Núcleo de Pesquisa e Documentação Sobre o Oeste do Paraná (CEPEDAL/UNIOESTE). ${ }^{3}$

2 NEIDE. [Carta]. Marechal Cândido Rondon, 19/10/1983. Carta ao Deputado Gernote Kirinus, pede ajuda para conseguir a aposentadoria. Acervo de correspondências arquivado no CEPEDAL/UNIOESTE. As citações das correspondências serão apresentadas da forma que aparecem nas cartas, respeitando a maneira como o remetente a escreveu, corrigindo apenas as palavras que dificultem a compreensão do leitor sobre o sentido da mesma na composição das frases. Serão adotados pseudônimos para designar os remetentes.

${ }^{3}$ Gernote Gilberto Kirinus, natural do Rio Grande do Sul, exerceu grande parte de sua militância político-religiosa no Oeste do Paraná, entre os anos 1975 a 1990, durante os conflitos para desapropriação de áreas e "pagamento justo" pelas terras frente ao empreendimento empresarial da Usina Hidroelétrica Itaipu, compondo ações da Comissão Pastoral da Terra. Foi pastor no distrito de Entre Rios e, posteriormente, 
Interessei-me, de imediato, pelas possíveis relações de poder contidas e estabelecidas na produção das mesmas, elaboradas por seus narradores e traduzidas por suas narrativas.

As leituras destas cartas me permitiram refletir sobre o contexto histórico em que estas pessoas estavam inseridas, a maneira como viviam, bem como suas dificuldades, anseios e perspectivas. Ao considerar essas correspondências como fontes de investigação, elas se tornaram base para o questionamento que procuro desenvolver com o projeto em andamento. Por meio das cartas é possível perceber as ambiguidades e as tensões expressas nas narrativas dos remetentes, bem como as pressões e interesses que os sujeitos envolvidos sinalizam sobre suas práticas e sobre sua condição de classe.

Ao adotar o conceito de classe, muito debatido no meio acadêmico, neste trabalho nos aproximamos da concepção indicada por Thompson, em que ao apresentar sua obra sobre a formação da classe trabalhadora inglesa destaca que

Por classe, entendo um fenômeno histórico, que unifica uma série de acontecimentos díspares e aparentemente desconectados, tanto na matériaprima da experiência como na consciência. Resalto que é um fenômeno histórico. Não vejo a classe como uma "estrutura", nem mesmo como uma

ampliando para todo o município de Marechal Cândido Rondon. Conferir essa imagem de Kirinus, por exemplo em: MEZZOMO, Frank A. Entrevista. A cruz e a política - leituras do pastor e político Gernote Kirinus. História Unisinos, São Leopoldo, v.12, n. 3, p. 285-296, set./dez. 2008. 
"categoria", mas como algo que ocorre efetivamente (e cuja ocorrência pode ser demonstrada) nas relações humanas. ${ }^{4}$

Nessa direção é possível perceber nas fontes elementos de identificação de classe entre os narradores, por meio da vida com dificuldades no campo, por residirem em Marechal Cândido Rondon, no referido momento histórico. E mais, por caracterizarem um modo de viver em disputa e em distinção de outros que se sobrepunham ao seu naquele momento de mecanização e expansão produtiva no meio rural.

A diversidade de solicitações, pedidos, queixas, relatos e temas encontrados me chamaram a atenção para observar o que esses sujeitos enfrentavam. $\mathrm{O}$ fato mais interessante foi notar que muitas dessas experiências eram compartilhadas entre os que viviam no campo na passagem da década de 1970 para 1980.

Tais dificuldades podem ser observadas em alguns fragmentos das cartas que discutirei, em que os mesmos reivindicam auxílio para um conjunto de questões que dificultam o seu modo de viver, desde tratamentos médicos como o faz o senhor Celso: "olha Gernote nós aqui em casa somos azarados não dá mais a explicar. Em primeiro lugar

\footnotetext{
${ }^{4}$ THOMPSON, E, P. A formação da classe operária. Rio de Janeiro: Paz e Terra, 1987. V.1
} 
nós todos estamos doentes e machucados." como aponta dona Neide: "e eu trabalho de doméstica, mais eu sofro muito, só Deus que sabe. Será que o Sn poderia me arrumar aposentadoria?".6.

Neste sentido, o acúmulo de necessidades para a sobrevivência e anseios para o bem estar familiar também elencaram demandas como a escolarização dos filhos e a preocupação com o futuro destes. A educação foi uma pauta presente em várias cartas, algo que exigia um universo de identificações tanto de necessidades como de proximidade com o deputado, procurando garantir a possível "bolsa de estudo": "meus pais e meus irmãos ajudaram o senhor para ganhar, agora o senhor ten que ajudar eu um pouco, para poder continuar meu estudo eu não quero abandonar meu estudo por favor arrume bolsa de estudo para $\operatorname{mim} " 7$.

Essa diversidade, estes indícios, foi importante para me permitirem ampliar o enfoque da questão inicial e elencar múltiplos elementos significativos nas vidas de tais sujeitos naquele momento histórico. A partir da pauta educacional, pode ser observado o que esta

5 CELSO. [Carta]. Marechal Cândido Rondon, 11/01/1982. Carta ao Deputado Gernote Kirinus, solicita ajuda para conseguir tratamento médico para si, e para seus familiares. Acervo de correspondências arquivado no CEPEDAL/UNIOESTE.

6 NEIDE. [Carta]. Marechal Cândido Rondon, 19/10/1983. Carta ao Deputado Gernote Kirinus, pede ajuda para conseguir a aposentadoria. Acervo de correspondências arquivado no CEPEDAL/UNIOESTE.

7 JOANA. [Carta]. Marechal Cândido Rondon, sem data de envio, a carta foi respondida em 09/06/1983. Carta ao Deputado Gernote Kirinus, solicita bolsa de estudo. Acervo de correspondências arquivado no CEPEDAL/UNIOESTE. 
representava tanto para os pais como para os filhos; as dificuldades para mantê-la, seja pelo custo das mensalidades, pelo transporte ou pela necessidade de se trabalhar ao invés de estudar. Questões que se interligam, e assim não podem ser analisadas separadamente.

Pautei-me, para tal análise, nas contribuições teóricas ofertadas por autores como Almeida, Calvo, Cardoso, procurando pensar sobre como eram as condições de viver e trabalhar em Marechal Cândido Rondon, entre 1970 e 1980. Em sua obra, estes autores demonstram as contribuições da linha de pesquisa "Trabalho e Movimentos Sociais", e, portanto, contribuindo para buscar certos procedimentos com a realização deste trabalho:

Recuperar a experiência histórica de diversos sujeitos sociais em seus múltiplos e diversificados aspectos, entendendo como as pessoas constroem seus espaços e territórios, deixando neles suas marcas: discutir as variadas experiências dos trabalhadores analisando o seu fazer-se enquanto classe em seus múltiplos sentidos e práticas; refletir sobre o significado das práticas sociais diferenciadas que estão no campo das vivências, bem como no dos valores e dos interesses, a fim de entender o social como um lugar de tensões; são objetivos que compõem universo das nossas preocupações maiores. ${ }^{8}$

\footnotetext{
${ }^{8}$ ALMEIDA, Paulo Roberto de; CALVO, Célia Rocha. CARDOSO, Heloísa Helena Pacheco. Trabalho e movimentos sociais: histórias, memórias e produção historiográfica. In: CARDOSO, Heloísa Helena Pacheco; MACHADO, Maria Clara 
Deste modo, com a adoção desta perspectiva de análise como suposto, procurei discutir as evidências presentes nas fontes, procurando identificar como esses agricultores se identificam e se posicionam nas relações de poder como interlocutores nas correspondências, vendo em que universo de relações eles estão inseridos e fazem parte, focalizando suas necessidades, expectativas e seus limites classistas.

Ainda, observando as propostas investigativas, Déa Ribeiro Fenelon sugere a importância da História Social para trabalhar com temáticas não questionadas/debatidas por algumas outras vertentes historiográficas, ou quando abordadas são apresentadas em um "segundo plano". O que para essa pesquisa se torna significativo apresentar o processo de desigualdades vivenciado e problematizado por quem age nele. Pois, como a autora destaca

nesta parte da questão não se pode deixar de reconhecer que, por criticar a história construída de cima para baixo, a História Social coloca ênfase em outros sujeitos, que não reis, políticos ou parlamentares, como capazes de fazer a História, sem transformá-los outra vez em vilões e novos heróis. Mais preocupada com processos coletivos, com grupos voltados para o interesse geral, consegue trabalhar na direção da democratização da História

Tomaz (Orgs.) História: narrativas plurais, múltiplas linguagens. Uberlândia: EDUFU, 2005, p. 11-16. 
podendo, em algumas variantes, enfatizar concepções que buscam explorar as contradições de classe como suposto de suas análises. ${ }^{9}$

As fontes me permitiram refletir sobre quem são e como muitos desses sujeitos são representados pela historiografia em um contexto muitas vezes tido como definidor da dinâmica história. Meu interesse é problematizar e questionar tais interpretações e visibilidades do processo histórico na passagem da década de 1970 para a década de 1980 em Marechal Cândido Rondon.

Valderice e Ricardo Rippel, ao examinar o desenvolvimento do Oeste do Paraná sobre a ótica da reconcentração fundiária, imigração e como a educação se insere nesse processo, entre 1950 e 2000, trazem a seguinte visão sobre o que ocorreu nesta localidade:

a partir da década de 1970, com a modernização da produção agrícola regional com vistas à exportação, ocorre uma grande alteração na capacidade de absorção e manutenção de mão de obra rural, resultando numa forte queda no fluxo de imigrantes para a região. Isso, mais as dificuldades observadas no setor agrícola do país no final da década gerou diversos problemas sociais e econômicos e provocou, a partir de 1980, um declínio substancial nas condições ali existentes, resultando num movimento de expulsão de pequenos proprietários

9 FENELON, Déa et al. Muitas memórias, outras histórias. São Paulo: Olho d'água, 2004. 
de suas áreas, tal qual apontado por Magalhães (1996). ${ }^{10}$

Ao relevarem o processo de "modernização da produção" (que por vezes também é denominado como "mecanização no campo" e/ou "capitalismo agrário") os autores não discutem o complexo enredo de implicações dessas mudanças na vida de trabalhadores rurais e pequenos proprietários empobrecidos na dinâmica de capitalização das atividades no campo. Essa "explicação" síntese, apresentada pelos autores, simplifica as lutas e expropriações vivenciadas nesse processo, tomando esse processo como natural e pacífico.

Muitas das atividades rurais que antes eram realizadas de forma manual passam a ser substituídas pelo trabalho "automático" com a utilização de máquinas e auxiliadas com implementos. Alguns trabalhadores sem ter mais a antiga profissão e moradia garantida tendem a procurar novas alternativas de trabalho, assim como alguns pequenos proprietários tentam se "adaptar" à nova situação rural, conseguindo ou não permanecerem neste ambiente. Em ambos os casos isto não ocorreu sem disputas e desigualdades de possibilidades entre eles, algo marcado por fissuras e tensões. ${ }^{11}$

${ }^{10}$ RIPPEL, Ricardo; RIPPEL, Valderice Cecília Limberger. Migração, Educação e Desenvolvimento: o caso dos chefes de família imigrantes no Oeste do Paraná uma análise de 1950 a 2000. In: Anais... XVI Encontro Nacional de Estudos Populacionais, Caxambu-MG: ABEP, 2008.

${ }^{11}$ Sobre esse processo de expropriação e alteração nas relações no campo, Freitas e Santos (2013) e Magda Regina Martins Costa (2013) indicam, em suas produções, fontes que apontam para tais embates, envolvendo trabalhadores rurais e pequenos 
E nesse caminho, o trabalho de Freitas e Santos ao problematizarem as mudanças nas relações no campo, por meio da análise da presença dos trabalhadores rurais e proprietários, na região Oeste do Paraná, destacam que:

Embora as atividades agroindustriais continuem expandindo e, cada vez mais, elenquem novas obrigações na manutenção das propriedades rurais, a permanência de trabalhadores e acomodação dos mesmos nas relações de trabalho no campo é algo bem controverso. ${ }^{12}$

Assim, os fatores que levaram o "movimento de expulsão de pequenos proprietários de suas áreas" vão além dos que foram apresentados pelos autores Valderice e Ricardo Rippel. Na carta abaixo, Clemente, como pequeno proprietário rural, vivendo as agruras do início da década de 1980 aponta que:

o negócio para o pequeno Agricultor não está nada bom e as perspectivas so tivera em vez de melhorar, piorá cada dia maiz e maiz, as pequenas chances que o pequeno proprietário de terra quase não podem ser usufruído por ele porque as dispesas se tornam tão

proprietários no processo de mecanização no campo. Esses elementos podem ser encontrados em notícias do programa de rádio, em processos trabalhistas e cíveis, assim como em entrevistas, utilizadas por esses autores como fonte para problematização.

${ }^{12}$ FREITAS, Sheille Soares de; SANTOS, Carlos Meneses de Sousa. Trabalhadores rurais e senhores de terra: nos campos da agroindustrialização. Oeste do Paraná na segunda metade do século XX e início do século XXI. 
grande que não vale a pena, a correria prácá e correria prála, passagem de onibus $[\ldots]^{13}$

Mesmo com as dificuldades, a "correria" a que Clemente se refere nos indica que ele busca alternativas para permanecer no campo, de melhorar sua condição como pequeno proprietário, ora trabalhando em outras propriedades, fazendo outros serviços para aumentar a renda da família, ou arrendando parte da terra. Portanto, "há, deste modo, brechas para se visualizar um horizonte indefinido, eivado de interesses que se confrontam e de valores que se embatem" $" 14$.

E, a partir da construção de alternativas ao processo, para permanecerem no espaço rural, estes vão reavaliando sua própria permanência no campo, uma vez que "para o pequeno agricultor" a situação "piora cada dia maiz e maiz".

No trabalho da Denise Langer, ao discutir a escolarização no campo em Marechal Cândido Rondon, ela destaca a oportunidade daqueles que não possuem seu próprio maquinário (tratores, colheitadeiras, entre outros implementos agrícolas) de prepararem suas terras e/ou desenvolverem outras atividades que demandem de "ajuda"

\footnotetext{
${ }^{13}$ CLEMENTE. [Carta]. Volta Gaúcha, Marechal Cândido Rondon, 25/03/1980. Carta ao Deputado Gernote Kirinus, relato sobre as condições do pequeno proprietário, sobre os custos da escola (mensalidade e transportes) e sobre a administração do Governo. Acervo de correspondências arquivado no CEPEDAL/UNIOESTE.

${ }^{14}$ FREITAS, Sheille Soares de; SANTOS, Carlos Meneses de Sousa. Trabalhadores rurais e senhores de terra: nos campos da agroindustrialização. Oeste do Paraná na segunda metade do século XX e início do século XXI.
} 
de outros agricultores, por meio de laços de solidariedade e troca de serviços, onde

Em minha vivência no campo foi possível perceber a solidariedade dos pequenos proprietários rurais e arrendatários em tempo de plantio, colheita ou preparo da terra, ou mesmo no compartilhamento inicial do tanque para o leite. Grande parte dos vizinhos se reúne para trabalhar em grupo, pois assim todos trabalham na terra de um e, quando aquela está pronta, vão para outra e assim até quando todas as propriedades envolvidas estiverem preparadas. Essa ação coletiva de parceria e no reconhecimento de necessidades comuns, acontecia/acontece na propriedade de pequenos agricultores familiares que resistem a um processo de concentração de propriedades e mecanização das atividades que exigem grande vulto de capital e retira-os, em grande medida, da participação do mercado. ${ }^{15}$

Como se percebe, os pequenos proprietários e trabalhadores rurais ao realizarem esse tipo de relação, mesmo reconhecendo suas limitações frente ao processo de mecanização, buscam maneiras de "se adequarem ao sistema", permanecendo no campo, local onde muitos nasceram, cresceram. Langer (2012) ainda acrescenta:

${ }^{15}$ LANGER, Denise. Entre cartilhas e roçado: a escolarização como pauta na vida de trabalhadores e proprietários (Marechal Cândido Rondon-PR, 1960-1980). Trabalho de Conclusão de Curso (Graduação em História) Centro de Ciências Humanas, Educação e Letras. UNIOESTE, Marechal Cândido Rondon, 2012. 
A dificuldade do pequeno proprietário, trabalhador meeiro e arrendatário, leva a desenvolver outras atividades conjuntas, ou pontencializar outros membros da família como trabalhadores, como é o caso de Emilio, que manteve, mesmo durante o tempo de professor, uma produção de subsistência e venda limitada de produtos: quando eu lecionava tinha lavora, mas tudo terra arrendada né? Mas lavora e bicharada nunca larguei, desde piá era o xodó e a gente se criô junto com o pai ai sempre com bicharada e um gado, uma vaca de leite, galinha, uns porco, sempre tem que tê, nem que não tem pra vendê, mas se tu tem pra te mantê, já tá bom né? Não precisá comprá carne. ${ }^{16}$

Vejamos agora como os autores Peris e Braga apresentam a saída do campo como resultado da mecanização rural em sua obra sobre a "Evolução e caracterização do Sistema Educacional", onde discutem a educação no Oeste do Paraná e os desdobramentos da "modernização da agricultura":

Por diferentes razões, a população abandonou o campo em busca dos centros urbanos. Os proprietários de terras foram para os centros das cidades onde os terrenos eram mais valorizados e tiveram fácil acesso ás escolas. Os não proprietários

\footnotetext{
${ }^{16}$ LANGER, Denise. Entre cartilhas e roçado: a escolarização como pauta na vida de trabalhadores e proprietários (Marechal Cândido Rondon-PR, 1960-1980). Trabalho de Conclusão de Curso (Graduação em História) Centro de Ciências Humanas, Educação e Letras. UNIOESTE, Marechal Cândido Rondon, 2012.
} 
de terras, com renda baixa, não tinham condições de adquirirem terrenos nos centros das cidades. Tiveram de se instalar nas periferias, onde o preço do terreno era mais baixo, não tendo acesso facilitado à escola. Segundo EMER (1991), os filhos dos proprietários de terras tiveram acesso à escolarização rural. Quando se urbanizaram, passaram a residir nos centros, próximos às escolas já existentes. Estas pessoas que retomam aos estudos, após a urbanização, passaram a disputar os espaços de trabalho urbano (comércio e serviços). Os expulsos do campo, pela modernização da agricultura, que foram para as periferias das cidades, continuaram sem escola. ${ }^{17}$

Quais são as diferentes razões? A população realmente abandonou o campo ou se viu obrigada a adotar esta medida? E como os pedidos de bolsa de estudo, já mencionados, poderiam ser percebidos nesse movimento de mudanças? Não é uma tentativa (tanto por parte de proprietários de terras e não proprietários de terra como designa os autores) de terem acesso a educação?

Langer ainda aponta fatores e condições que influenciaram no processo educacional entre 1960 a 1980, relacionando as mudanças que ocorreram no campo, porém o faz reconhecendo que:

${ }^{17}$ PERIS, Alfredo F., BRAGA, Eliezio G. Capítulo 13 - Evolução e Caracterização do Sistema Educacional. In: PERIS, Alfredo F. (Coord.). Projeto Macroregião do Oeste do Paraná. Relatório Projeto Oraculus. Cascavel: UNIOESTE/ITAIPU/ECONOMIA. 2002. Disponível: 〈http://www.unioeste.br/projetos/oraculus/PMOP/index.htm> 
Por vezes, precisamos levar em consideração que as alterações nas relações do campo (mecanização e saída das pessoas do campo), os conflitos e desigualdades desse processo não se apresentam nas formulações financeiras do Poder Público, por exemplo. Mas encontram diálogo com as práticas e atuações dos sujeitos nesses espaços, por isso privilegiamos essas relações. ${ }^{18}$

$\mathrm{O}$ aprofundamento da problemática proposta exige entender o trato metodológico dessas fontes como um procedimento fundamental na direção da pesquisa e do caminho investigativo, pois expressa o suposto teórico que informa o uso documental e as questões construídas para utilização desse material, que me fazem questionar determinadas historiografias e visões sobre o que foi vivido como transformação para quem vivia no campo como trabalhador rural ou proprietário sem capital para inserção nos projetos de expansão agroindustrial na região.

Aproveitando o indicativo de Fenelon sobre a relevância da investigação histórica e o procedimento que propõe, não queremos apenas ampliar a leitura sobre essa temporalidade passada, mas

queremos inverter a relação passado/presente para tornar mais explícita a relação do momento do qual partimos, ou seja, entre nossos problemas, nossas lutas e a experiência histórica de outros momentos,

\footnotetext{
${ }^{18}$ LANGER, Denise. Entre cartilhas e roçado: a escolarização como pauta na vida de trabalhadores e proprietários (Marechal Cândido Rondon-PR, 1960-1980). Trabalho de Conclusão de Curso (Graduação em História) Centro de Ciências Humanas, Educação e Letras. UNIOESTE, Marechal Cândido Rondon, 2012.
} 
para conseguir assim politizar a história que transmitimos e produzimos. ${ }^{19}$

Como escrito anteriormente, a educação é uma das principais pautas nas cartas enviadas. Por isso, é um fator importante para começarmos a discutir nossas propostas nesta pesquisa, principalmente porque nas descrições/interpretações das narrativas dos pequenos proprietários, é nítida a valorização do estudo e, do mesmo modo, é possível perceber as dificuldades de mantê-lo como prática.

As condições de vida desses narradores, composta por trabalhadores rurais e pequenos proprietários empobrecidos no processo de capitalização das relações de produção no campo no Oeste do Paraná, faz com que visualizemos que a escolarização é apenas uma das expectativas a serem confrontadas em sua condição de classe.

Em artigo de Santos e Freitas, que se propõe a problematizar a relação entre professores e alunos (compostos em sua maioria por trabalhadores) que frequentam a escola pública, constituindo um diálogo nesse espaço onde as tensões e as pressões presentes na identificação de classe possam ser debatidas, apresentam assim um ambiente propício para refletir sobre o tempo em que vivem e os sentidos da escolarização. Apontam como sugestão que:

\footnotetext{
${ }^{19}$ FENELON, Déa. O historiador e a cultura popular: história de classe ou história do povo? História \& Perspectivas, Uberlândia, n. 40, p. 27-51, jan./jun. 2009
} 
Ao fazer a composição dessa imagem em um campo de relações ampliado na condição de classe compartilhada pelos trabalhadores que frequentam as salas de aula, percebemos que a presença que imprimem nesses espaços não é tranquilo. Estabelecer as possibilidades para conseguir sentar nas carteiras escolares pode indicar modos de vida limitados nas relações de classes. ${ }^{20}$

E uma dessas possibilidades destacadas pelos referidos autores, que no nosso caso é encontrada nas cartas, são os pedidos de bolsa de estudo ao deputado. É uma alternativa buscada para garantirem a escolarização $^{21}$, num momento histórico em que em muitas das instituições de ensino solicitavam pagamento de mensalidades, do material escolar, além dos custos com transporte, uniformes etc.

O simples fato dos remetentes avaliarem que por meio das correspondências com o Deputado (nas quais admitem suas limitações e distinções com o interlocutor) poderiam conseguir ou manter o acesso ao ambiente escolar dos filhos sugere como veem sua inserção nas relações de poder e se utilizam dessa desigualdade para isto. $\mathrm{O}$ ato de narrarem suas trajetórias e condições de vida aparece como uma oportunidade de construir algum tipo de benefício - comum para

\footnotetext{
${ }^{20}$ FREITAS, Sheille Soares de; SANTOS, Carlos Meneses de Sousa. Trabalhadores nas salas da escolarização: o ensino de história como enredo possível para a discussão da identificação de classe. Trabalho \& Educação, Belo Horizonte, v.19, n. 2, mai/ago 2010.

${ }^{21}$ Vale ressaltar que os pedidos de bolsas de estudos eram, em muitos casos, feitos pelos pais e pelos próprios estudantes e seguiam, muitas vezes, acompanhados de outras demandas.
} 
aqueles que traziam algum vínculo anterior com o deputado - e, assim, pressionar para a construção de possibilidades de alterarem sua realidade.

Ao procurar expor essa questão, apresentarei agora alguns fragmentos de duas cartas produzidas por agricultores residentes na área rural dos distritos de Marechal Cândido Rondon à época. Como primeiro elemento que gostaria de destacar é o tratamento inicial que os mesmos designam ao deputado, com atribuição de palavras como "Estimado Deputado" e "Caro Amigo Deputado!".

Vejam bem, essas palavras são escolhidas para a narrativa e possuem uma intencionalidade. Elas não são colocadas por casualidade no texto da correspondência, mas para demonstrar que existe uma relação de reconhecimento da aproximação entre eles, apesar da noção de "Deputado" ficar destacada no vocativo que anuncia as intenções da produção da carta e o reconhecimento da distinção entre ambos.

A carta escrita por Terezinha, pequena proprietária rural, resalta sua condição de mãe de seis filhos. ${ }^{22}$ Ela destaca o empenho para que todos mantenham os estudos, mesmo que para esta feita seja necessário passar por algumas restrições. $\mathrm{O}$ objetivo principal, de solicitar o auxílio do deputado é conseguir bolsa de estudo para os seus filhos, como veremos em um fragmento de sua carta a aquele: "Gostaria que o

${ }^{22}$ TEREZINHA. [Carta]. Quatro Pontes, Marechal Cândido Rondon, 03/01/1980. Carta ao Deputado Gernote Kirinus, solicita bolsa de estudo para os filhos. Acervo de correspondências arquivado no CEPEDAL/UNIOESTE. 
senhor me informasse com quem eu poderia conseguir bolsa para a turma do ginásio".

Percebemos em sua narrativa a referência a problemas sobre a situação dos proprietários rurais e a vida no campo indicando como era a composição familiar, os gastos e empenho de todos no trabalho. A partir da pauta da escolarização percebemos outros aspectos que ajudam a tentar compreender as razões de pedirem ajuda: "Nossa situação financeira não alcança até as alturas porque vivemos em 8 na familia numa area de terra de 6 alqueires. Com estas intempéries não há quem aguenta",23

$\mathrm{Na}$ carta escrita por Clemente, também proprietário rural da região Oeste do Paraná, o remetente não busca diretamente conseguir uma bolsa de estudo para o filho, mas em sua narrativa apresenta as dificuldades que o fizeram transferi-lo do ginásio onde estudava, em Entre Rios $^{24}$ para o de Margarida ${ }^{25}$, descrevendo os custos da mensalidade, o transporte e o possível aumento da mensalidade, fatores financeiros que determinaram a mudança de uma instituição de ensino para a outra. Junto a isso, não deixa de destacar o conjunto de questões que envolvem a vida em sua integralidade:

\footnotetext{
${ }^{23}$ TEREZINHA. [Carta]. Quatro Pontes, Marechal Cândido Rondon, 03/01/1980. Carta ao Deputado Gernote Kirinus, solicita bolsa de estudo para os filhos. Acervo de correspondências arquivado no CEPEDAL/UNIOESTE.

24 Entre Rios, inicialmente foi distrito de Marechal Cândido Rondon, até 18/06/1990, quando é elevado a categoria de município com denominação de Entre Rios do Oeste. ${ }^{25}$ Distrito de Marechal Cândido do Rondon - Paraná.
} 
[...] ainda pra mim se torna ainda bastante oneroso porque agente nem sabe maiz se virar com esta crise que estamos emfrentando a onde só tem inflasão no que o colono compra, mas não para aquilo que tem para vender, pagar os seos pepinus com gastos de médicos, remedios, vestuarios ou vestimentas, material escolar e o custo de vida, ou seja generos alimentícios que a gente não produs. ${ }^{26}$

Evidentemente em sua narrativa se permite observar o quadro de relações sociais e o contexto histórico no qual está inserido, visualizando os conflitos cotidianos que este sujeito enfrenta. $\mathrm{O}$ trabalho familiar é um dos componentes presentes tanto na fala de Terezinha quanto de Clemente e da efetiva participação dos estudantes no serviço diário dos pais.

A oportunidade dos filhos estudarem constitui alternativas para o futuro dos mesmos e isso justificaria os sacrifícios que os pais fazem para tornar viável tal necessidade de escolarização. Essa série de limitações, compartilhadas por pequenos proprietários que seguem descapitalizados no processo de expansão produtiva no campo, também foi identificado por Langer, onde ela destaca que essa tentativa de manter os filhos estudando em alguma medida indicava um interesse em alterar

${ }^{26}$ CLEMENTE. [Carta]. Volta Gaúcha, Marechal Cândido Rondon, 25/03/1980. Carta ao Deputado Gernote Kirinus, relato sobre as condições do pequeno proprietário, sobre os custos da escola (mensalidade e transportes) e sobre a administração do Governo. Acervo de correspondências arquivado no CEPEDAL/UNIOESTE. 
Limites que foram valorados também por outros pais, que se denominavam agricultores e que reconheciam o esforço do acúmulo de trabalho e de privações como a forma de lutarem para abertura de novos horizontes aos filhos em uma sociedade que percebiam relações de poder que não lhes favoreciam como esperavam. ${ }^{27}$

Pensando nessa formulação, vejo na construção das correspondências a esperança de que com suas reivindicações e narrativas sobre a rotina no campo, algo possa ocorrer para atender suas expectativas de vida. Assim, encerram as cartas com frases do gênero "fico lhe muito grata, espero ser atendida", ou "[esse é o] meo desabafo", tentando selar o compromisso do Deputado com suas questões.

Essas são algumas das questões que pretendo problematizar nos próximos trabalhos, baseada nas cartas e suporte teórico; para, posteriormente, relacionar tais documentos com reportagens dos jornais de Marechal Cândido Rondon.

Partindo de inquietações do presente que nos fizeram olhar para essas fontes, avaliamos que elas não apontam um recorte do passado, que não se vincula à nossa atualidade, mas sugere questões que dialogam com problemáticas recentes e desigualdades de nosso tempo

\footnotetext{
${ }^{27}$ LANGER, Denise. Entre cartilhas e roçado: a escolarização como pauta na vida de trabalhadores e proprietários (Marechal Cândido Rondon-PR, 1960-1980). Trabalho de Conclusão de Curso (Graduação em História) Centro de Ciências Humanas, Educação e Letras. UNIOESTE, Marechal Cândido Rondon, 2012
} 
permite questionar relações complexas e contraditórias envolvendo modos de viver no campo e práticas de escolarização de trabalhadores e proprietários empobrecidos no Oeste do Paraná.

Essas considerações compõem o primeiro mote de questões da minha pesquisa de iniciação científica. Ao catalogar mais de trezentas cartas, selecionei dentre estas, a partir do recorte de tempo e lugar, as que mais foram significativas para o questionamento que procuro desenvolver. Uma análise inicial sujeita a novas problematizações e interpretações com o desenvolvimento e amadurecimento da mesma.

\section{Referências}

ALMEIDA, Paulo Roberto de; CALVO, Célia Rocha. CARDOSO, Heloísa Helena Pacheco. Trabalho e movimentos sociais: histórias, memórias e produção historiográfica. In: CARDOSO, Heloísa Helena Pacheco; MACHADO, Maria Clara Tomaz (Orgs.) História: narrativas plurais, múltiplas linguagens. Uberlândia: EDUFU, 2005, p. 11-16.

COSTA, Magda R. M. Trabalhadores em Santa Rita D'Oeste: problematizando modos de viver e trabalhar no campo e na cidade. Trabalho Final PDE. 2013.(mimeo)

FENELON, Déa et al. Muitas memórias, outras histórias. São Paulo: Olho d'água, 2004. 
. O historiador e a cultura popular: história de classe ou história do povo? História \& Perspectivas, Uberlândia, n. 40, p. 27-51, jan./jun. 2009

IPARDES. Caderno Estatístico - Município de Marechal Cândido Rondon. Curitiba: IPARDES, 2013.

LANGER, Denise. Entre cartilhas e roçado: a escolarização como pauta na vida de trabalhadores e proprietários (Marechal Cândido Rondon-PR, 1960-1980). Trabalho de Conclusão de Curso (Graduação em História) Centro de Ciências Humanas, Educação e Letras. UNIOESTE, Marechal Cândido Rondon, 2012.

PERIS, Alfredo F., BRAGA, Eliezio G. Capítulo 13 - Evolução e Caracterização do Sistema Educacional. In: PERIS, Alfredo F. (Coord.). Projeto Macroregião do Oeste do Paraná. Relatório Projeto Oraculus. Cascavel: UNIOESTE/ITAIPU/ECONOMIA. 2002. Disponível:

<http://www.unioeste.br/projetos/oraculus/PMOP/index.htm>

RIPPEL, Ricardo; RIPPEL, Valderice Cecília Limberger. Migração, Educação e Desenvolvimento: o caso dos chefes de família imigrantes no Oeste do Paraná uma análise de 1950 a 2000. In: Anais... XVI Encontro Nacional de Estudos Populacionais, Caxambu-MG: ABEP, 2008. 
FREITAS, Sheille Soares de; SANTOS, Carlos Meneses de Sousa. Trabalhadores nas salas da escolarização: o ensino de história como enredo possível para a discussão da identificação de classe. Trabalho \& Educação, Belo Horizonte, v.19, n. 2, mai/ago 2010.

- Trabalhadores rurais e senhores de terra: nos campos da agroindustrialização. Oeste do Paraná na segunda metade do século XX e início do século XXI. (mimeo)

THOMPSON, E, P. A formação da classe operária. Rio de Janeiro:

Paz e Terra, 1987. V.1 